\title{
Modified-release Granule Dosage Form
}

National Cancer Institute

\section{Source}

National Cancer Institute. Modified-release Granule Dosage Form. NCI Thesaurus. Code C149665.

Solid preparation consisting of granules showing a rate and/or place of release different from that of conventional-release granules. This deliberate modification is achieved by a special formulation design and/or manufacturing method. Modified-release granules are usually single-dose preparations intended for oral use, and include prolong ed-release, delayed release and pulsatile-release granules. 